\title{
Extraction-Atomic-Absorption Determination of Germanium with 2- Hydroxy-5-T-Butylphenol-4'-Methoxy-Azobenzene
}

\author{
A.M.Pashajanov
}

Institute of Catalysis and Inorganic Chemistry named after academician M.Nagiyev of Azerbaijan National Academy of Sciences, AZ 1143, H.Javid Ave. 113 Baku, Azerbaijan

aydin.pashajanov@gmail.com

\begin{abstract}
The interaction of germanium with 2-hydroxy-5-T-butylphenol-4'-methoxy-azobenzene $(\mathrm{HR})$ was studied. Optimum values of $\mathrm{pH}$ of solution are $3.5 \div 4.0$. Maximum light absorbance of the complex in n-butanol is in the range of $470 \div 480 \mathrm{~nm}$. Chloroform, dichloroethane, carbon tetrachloride, benzene, toluene, xylene, hexane and $n$-butanol were tested for extraction of the complex. The most effective extractant was found to be n-butanol used in further studies. Absorption spectrum indicates the formation of one complex. Ratio of components in the complex under optimum conditions were found by method of equilibrium shift and straight-line method of Asmus, they are equal to Ge:HR =1:2. Selectivity of extraction-atomic absorption determination of germanium was studied by using HR. Molar absorption coefficient equals to (4.0 \pm 4.2$) \cdot 10^{4}$. Beer's law was observed at concentrations of germanium $1 \div 10 \mathrm{mkg} / \mathrm{ml}$. Stability constant of germanium in $\mathrm{n}$-butanol was found to be $\beta_{\mathrm{k}}=3 \cdot 4 \cdot 10^{6}$. Calibration curve was linear at concentrations of germanium $1 \div 10 \mathrm{mkg} / \mathrm{ml}$. Selective and sensitive techniques of extraction-atomic absorption determination of germanium in different regions were developed.
\end{abstract}

\section{Keywords}

germanium, atomic-absorption, extraction, complexation.

\section{Academic Discipline And Sub-Disciplines}

Chemistry

\section{SUBJECT CLASSIFICATION}

Analytical chemistry, inorganic chemistry

\section{TYPE (METHOD/APPROACH)}

\section{Atomic-absorption, spectrophotometry, photometry.}

\section{INTRODUCTION}

Analytical chemistry of germanium has now reached significant progress. However the determination of lower concentrations of germanium is an urgent problem. Atomic-absorption (AA) method and physical-chemical analysis methods are promising for its solution. Direct atomic-absorption determination of low contents of Ge in complex objects is not always possible due to the effect of accompanying elements, as well as insufficient sensitivity. One of the promising methods of increasing selectivity and sensitivity of atomic-absorption technique is its use in combination with extraction [1-5].

Organic reagents are promising reagents for determination of germanium. Phenylfluorane and its derivatives, derivatives of aniline, pyrocatechin violet, stilbazo and others are often used in analytical chemistry of germanium [6-8]. However the reactions with these reagents are insufficiently selective.

In the present work the extraction conditions of germanium (IV) with 2-hydroxy-5-T-butylphenol-4'-methoxy-azobenzene were studied. Extraction-photometric and extraction-atomic determination methods of germanium in different objects were developed.

\section{EXPERIMENTAL}

\section{Reagents and instruments}

Standard $1.0 \cdot 10^{-3} \mathrm{M}$ solution of germanium was prepared with $\mathrm{GeO}_{2}$ dioxide of analytical reagent grade in distilled water by adding 1-2 drops of diluted $\mathrm{NaOH}$ and then it was neutralized by method [9]. Solution of germanium with concentration of $0.1 \mathrm{mg} / \mathrm{ml}$ was prepared by diluting standard solution. $3.5 \cdot 10^{-4} \mathrm{M}$ of 2-hydroxy-5-T-butylphenol-4'-methoxy-azobenzene was prepared by dissolution of precisely weighed amount in ethanol.

2-hydroxy-5-T-butylphenol-4'-methoxy-azobenzene $(\mathrm{HR})$ reagent was synthesized by using the method [10]. Content and structure of the reagent was determined by using elemental analysis, IR- and UV-spectroscopy. The reagent is a monoacid and has a general structural formula:

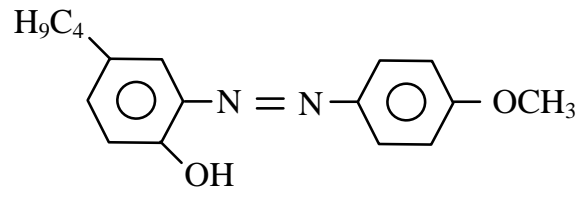

IR-spectrum - $3450 \mathrm{~cm}^{-1}$ (O-H arom.); $2960 \mathrm{~cm}^{-1}\left(\mathrm{C}-\mathrm{H}\right.$ from $\left.\mathrm{CH}_{3}\right) ; 3030 \mathrm{~cm}^{-1}\left(\mathrm{C}-\mathrm{H}\right.$ arom.); 1592, $1496,1464 \mathrm{~cm}^{-1}(\mathrm{C}=\mathrm{C}$ arom.); $1408 \mathrm{~cm}^{-1}(\mathrm{~N}=\mathrm{N}) ; 1168 \mathrm{~cm}^{-1}(\mathrm{C}-\mathrm{C}) ; 1264 \mathrm{~cm}^{-1}(\mathrm{C}-\mathrm{N}) ; 1136 \mathrm{~cm}^{-1}, 1104 \mathrm{~cm}^{-1}$ (arom. -O-C). 
$\mathrm{HCl}, \mathrm{H}_{2} \mathrm{SO}_{4}$ and ammonium acetate buffer solutions were used to create optimum acidity. lonic strength of solutions $(\mu=0,1)$ was formed by adding calculated amount of $1.0 \mathrm{M}$ solution of $\mathrm{KNO}_{3}$.

$\mathrm{pH}$ value of solutions was monitored by universal ionomer EV-74. Optical density of solutions was measured by spectrophotometer SF-46 and photoelectrocolorimeter KFK-2.

Atomic absorption of germanium was measured by using atomic-absorption spectrophotometer AAS-1N.

As light sources standard hollow cathode lamps were used. Optimum measurement conditions are listed in Table 1.

Table 1. Conditions of atomic-absorption determination of germanium.

\begin{tabular}{|c|c|c|c|c|}
\hline $\begin{array}{c}\text { Wavelength, } \\
\mathbf{n m}\end{array}$ & Slot width, $\mathbf{m m}$ & $\begin{array}{c}\text { Lamp current, } \\
\text { MA }\end{array}$ & Acetylene flow, I/h & $\begin{array}{c}\text { Consumption of nitrogen } \\
\text { oxide, I/h }\end{array}$ \\
\hline 265.2 & 0.5 & 20 & 200 & 180 \\
\hline
\end{tabular}

\section{Technique}

A certain amount of standard solution of germanium, $5 \mathrm{ml}$ of buffer solution with necessary pH value, $1.0 \mathrm{ml}$ of $\mathrm{HR}$ were poured into a separation funnel and stoppered tubes, diluted with distilled water till $20 \mathrm{ml}$, and resulting compound of $10 \mathrm{ml}$ $\mathrm{n}$-butanol was extracted and mixed a minute. After complete separation of phases the extract was sprayed on acetylenenitrogen oxide flame and atomic absorption of germanium was measured.

\section{RESULTS AND DISCUSSION}

\section{Effect of acidity of medium}

To study the complexation conditions of germanium with HR dependence curves of optical density on acidity of aqueous phase in a wide range of $\mathrm{pH}$ were recorded. $\mathrm{HR}$ with germanium (IV) in the range of $\mathrm{pH} 2.5 \div 6.0$ forms colored complex compound. Optimum acidity was found to be $\mathrm{pH} 4.0$ (Figure 1).

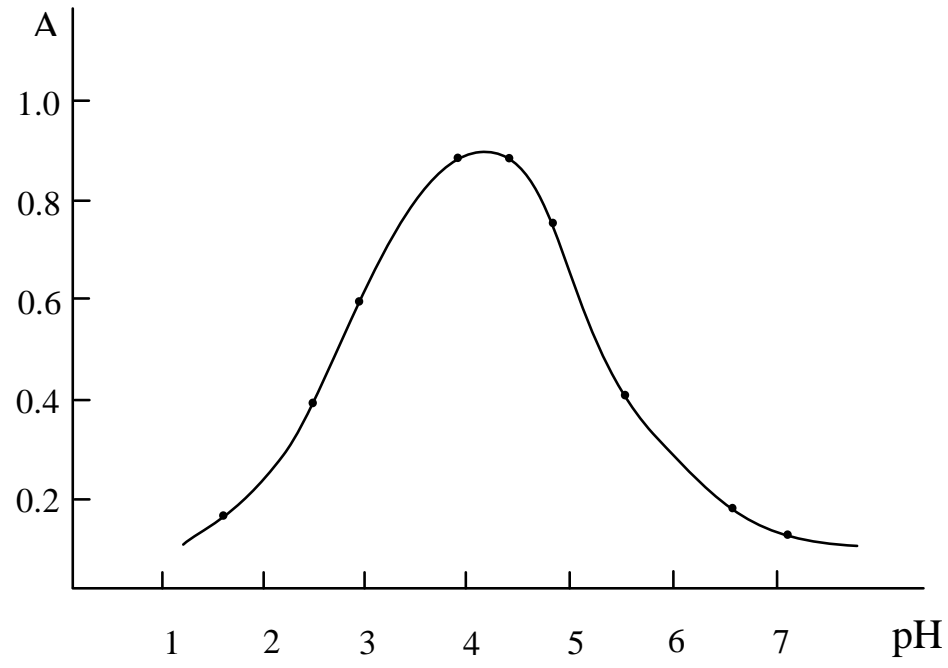

Fig 1: Effect of pH on complexation of Ge (IV).

$\mathrm{C}_{\mathrm{HR}}=3,9 \cdot 10^{-4} \mathrm{M} ; \mathrm{C}_{\mathrm{Ge}}=1,0 \cdot 10^{-3} \mathrm{M} ; \lambda=480 \mathrm{~nm} ; \mathrm{V}_{\text {org. }}=5 \mathrm{ml}$;

$l=0,5 \mathrm{~cm}$; background $-\mathrm{H}_{2} \mathrm{O}$; KFK-2.

Chloroform, dichloroethane, carbon tetrachloride, benzene, toluene, xylene, hexane and n-butanol were tested for extraction of the complex. The most effective extractant was n-butanol used in further researches.

Equilibrium concentration of germanium (IV) in aqueous phase was determined using atomic-absorption method. Amount of germanium in organic phase was found by the difference. In single extraction with n-butanol $98 \%$ of germanium (IV) was extracted.

\section{Effect of concentration of reagent}

A series of experiments with constant concentrations of germanium and variable concentration of reagent were carried out to study the effect of reagent concentration on the formation of complex. When amount of HR increases up to $3.2 \cdot 10^{-4} \mathrm{M}$ the extraction of germanium increases, and further increase of reagent amount does not affect on extraction of germanium.

The complex was formed soon after the components were mixed and was stable for two days. Equilibrium between phases was established for the moment of shaking. Optimum aqueous phase volume was $10 \mathrm{ml}$, organic phase was $5 \mathrm{ml}$. 


\section{Absorption spectra of the complex}

Under optimum conditions maximum absorption spectrum of the complex was observed at $470 \div 480$, maximum absorption spectrum of the reagent was observed at $380 \mathrm{~nm}$ (fig.2).

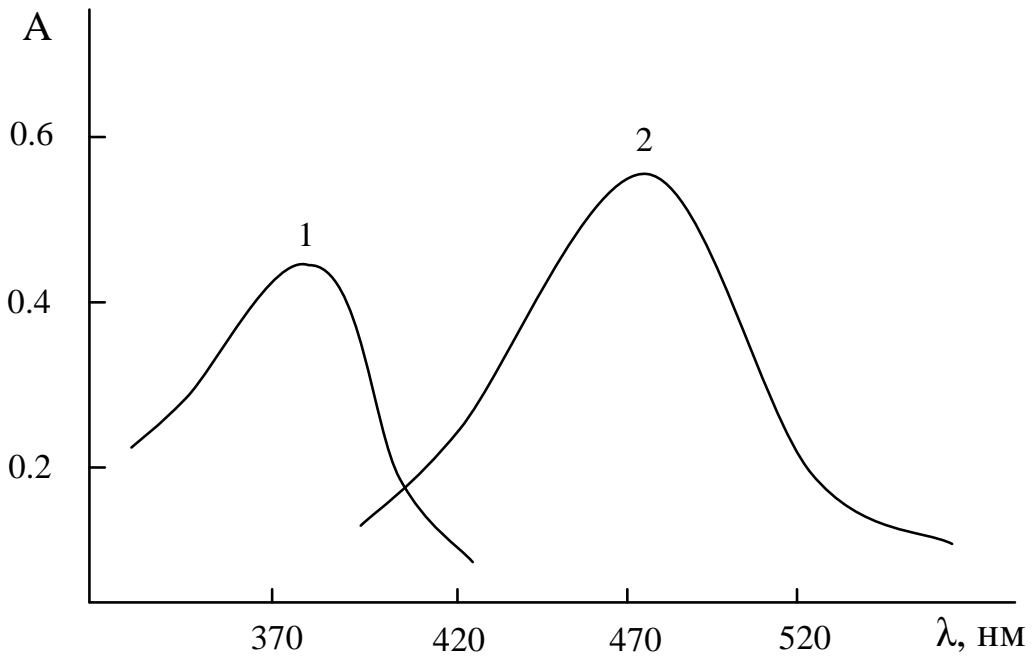

Fig 2: Absorption spectrum of extracts of reagent (1) and complex Ge(IV) (2); $\mathrm{C}_{\mathrm{HR}}=3,9 \cdot 10^{-4} \mathrm{M} ; \mathrm{C}_{\mathrm{Ge}}=1,0 \cdot 10^{-3} \mathrm{M} ; \mathrm{V}_{\mathrm{org}}=5 \mathrm{ml} ; \mathrm{l}=0,5 \mathrm{~cm} ; \mathrm{KFK}-2$.

Absorption spectrum indicates the formation of one complex.

Ratio of components in the complex under optimum conditions were found by method of equilibrium shift and straight-line method of Asmus, they are equal to $\mathrm{Ge}: \mathrm{HR}=1: 2[11]$.

According to stoichiometry of the complex and ionic state of components of the system formation reaction and extraction of homogeneous ligand complex of germanium (IV) can be shown as follows:

$$
\mathrm{GeO}^{+2}+2 \mathrm{HR} \rightarrow \mathrm{GeOR}_{2}+2 \mathrm{H}^{+}
$$

Stability constant of the complex of germanium in $n$-butanol $\beta \kappa=3.4 \cdot 10^{6}$ and equilibrium constant of complexation reaction $3.2 \cdot 10^{4}$ at $\mathrm{pH}=4.0$ were calculated by spectrophotometric data for $n$-butanol solution by using dependence of light absorbance of solutions on $\mathrm{pH}$.

Molar absorption coefficient of germanium calculated by Tolmachev method [11] equals to $\varepsilon=4.2 \cdot 10^{4}$. Calibration chart is linear for concentrations of germanium $1.0 \div 10.0 \mathrm{mkg} / \mathrm{ml}$.

\section{Influence of foreign ions}

Selectivity of extraction-atomic-absorption determination of germanium was studied by using HR.

Alkali, alkali-earth elements, and other foreign ions: $\mathrm{Cu}^{+2}(20), \mathrm{Zn}^{+2}(100), \mathrm{Hg}^{+2}(5), \mathrm{Ca}^{+2}(100), \mathrm{Mu}^{+2}(200), \mathrm{Ni}^{+2}(60)$, $\mathrm{Mo}^{+6}(200), \mathrm{Cr}^{+3}(400), \mathrm{Fe}^{+3}(100), \mathrm{Sn}^{+2}(10), \mathrm{Sb}^{+3}(15), \mathrm{Co}^{+2}(100), \mathrm{Cd}^{+2}(100), \mathrm{Al}^{+3}(350), \mathrm{Cl}^{-}(200), \mathrm{Br}^{-}(100)$ do not interfere with the determination of germanium with $\mathrm{HR}$.

Methods of extraction-atomic-absorption and extraction-photometric determination of germanium in different objects were developed.

These methods (EAA and EPh) were used in determination of germanium in objects of environment: oil coke and stratal waters.

\section{Determination of germanium in oil coke}

Sample weight $(3 \mathrm{~g})$ of finely crushed oil coke was well mixed with $4 \mathrm{~g}$ of anhydrous sodium sulfate. The mixture was placed into porcelain crucible with a cap and kept an hour at $900^{\circ} \mathrm{C}$ in a muffle furnace. Sintered mixture was leached with $20 \mathrm{ml}$ of water. $4 \mathrm{ml}$ of $30 \%$ hydrogen peroxide was added, boiled up to its full decomposition and the solution was evaporated till $10 \mathrm{ml}$. 
In oil coke $(3.21 \pm 0.01) \cdot 10^{-3} \%$ of Ge was found by atomic-absorption method, but $(2.95 \pm 0.04) \cdot 10^{-3} \%$ of Ge was found by photometric method.

\section{Determination of germanium in stratal waters}

$2 \mathrm{I}$ of oil water was acidified in $\mathrm{HCl}$, then $1 \mathrm{ml}$ of $20 \% \mathrm{FeCl}_{3}$ was added and $\mathrm{Fe}(\mathrm{OH})_{3}$ was deposited with ammonia. Filtered deposit was washed with $1 \%$ solution of $\mathrm{NH}_{4} \mathrm{Cl}$, dissolved with diluted $\mathrm{HCl}$, concentration of acid was brought to $9 \mathrm{~N}$ and Ge was determined by abovementioned technique. In sample $(4.10 \pm 0.01) \cdot 10^{-5} \mathrm{~g} / \mathrm{l}$ of Ge was found by atomic-absorption method, but $3.98 \cdot 10^{-5} \mathrm{~g} / \mathrm{l}$ of $\mathrm{Ge}$ was found by photometric method.

Table 2. Determination of germanium in objects of environment $(n=5 ; p=0.95)$

\begin{tabular}{|c|c|c|}
\hline Analyzed material & Atomic-absorption method & Photometric method \\
\hline Oil coke & $(3.21 \pm 0.01) \cdot 10^{-3} \%$ & $(2.95 \pm 0.04) \cdot 10^{-3} \%$ \\
Stratal water & $(4.10 \pm 0.01) \cdot 10^{-5} \mathrm{~g} / \mathrm{l}$ & $(3.98 \pm 0.02) \cdot 10^{-5} \mathrm{~g} / \mathrm{l}$ \\
\hline
\end{tabular}

Determination method of germanium was also used to analyze artificial mixtures conforming to the solutions of some alloys containing germanium. Validity was confirmed by standard addition method (Table.3).

Table 3. Results of extraction-atomic absorption and extraction-photometric determination of germanium in artificial mixtures $(n=5 p=0.95)$

\begin{tabular}{|c|c|c|c|}
\hline Method & $\begin{array}{c}\text { Added, } \\
\mathbf{m k g}\end{array}$ & $\begin{array}{c}\text { Found, } \\
\mathbf{~} \mathbf{k g}\end{array}$ & $\mathbf{S r}$ \\
\hline \multirow{3}{*}{$\begin{array}{c}\text { Extraction-atomic absorp- } \\
\text { tion }\end{array}$} & 4.0 & $3.85 \pm 0.04$ & 0.03 \\
\cline { 2 - 4 } & 5.0 & $4.90 \pm 0.03$ & 0.05 \\
\cline { 2 - 4 } & 10.0 & $9.98 \pm 0.04$ & 0.03 \\
\hline \multirow{2}{*}{$\begin{array}{c}\text { Extraction-photometric } \\
\text { method }\end{array}$} & 4.0 & $3.50 \pm 0.02$ & 0.05 \\
\cline { 2 - 4 } & 5.0 & $4.70 \pm 0.01$ & 0.08 \\
\hline
\end{tabular}

\section{CONCLUSIONS}

Complexation and extraction of germanium with 2-hydroxy-5-T-butylphenol-4'-methoxy-azobenzene was studied. Optimum condition of formation and extraction of the complex was found. Maximum light absorbance of a complex in $n-$ butanol was in the range of $470 \div 480 \mathrm{~nm}$. Optimum values of $\mathrm{pH}$ of solution are 3.5-4.0. Molar absorption coefficient equals to $(4.0-4.2) \cdot 10^{4}$. Stability constant of germanium in $n$-butanol was $\beta_{k}=3.4 \cdot 10^{6}$. Selectivity of extraction-atomic absorption determination of germanium was studied by using HR. Beer's law was observed at concentrations of germanium $1-10 \mathrm{mkg} / \mathrm{ml}$. Atomic-absortpion determination method of germanium was developed.

\section{REFERENCES}

1. Nazarenko V.A. 1973. Analytical chemistry of germanium.

2. Ivanov V.M. 1982. Heterocyclic nitrogen containing compounds. M. Nauka.

3. Zolotov Y.A., Kuzmin N.M. 1982. Concentrating of microelements. M. Chemistry.

4. Price V. 1976. Analytical Atomic-Absorption Spectroscopy. M. Mir.

5. Kharlamov I.P., Eremina G.V. 1982. Atomic-Absorption analysis in ferrous metallurgy. M. Metallurgy.

6. Sargar B.M., Anuse M.A. 2005. Solvent Extraction Separation of Germanium (IV) with N-n-Octylaniline as an Extractant. Journal of Analytical Chemistry. 463-467.

7. Soi Yin, Li Sheng. 2004. Determination of trace amount of germanium in charcoal by spectrophotometry and using 2,4-dichlorophenylfluorane. Han-Fu-Bin.

8. Umland F., Jansen A., Tearing D., Wyunsch G. 1975. Complex compound in analytical chemistry. M., Mir.

9. Korostelev P.P. 1964. Preparation of solutions for chemical analytical works. M. Nauka.

10. Gasimov V.T., Mejidov A.A. 1981. Coordination chemistry.

11. Bulatov M.I., Kalinkin I.P. 1976. Practical guidance on photocolorimetric and spectrophotometric methods of analysis. L., Chemistry. 


\section{Author' biography with Photo}

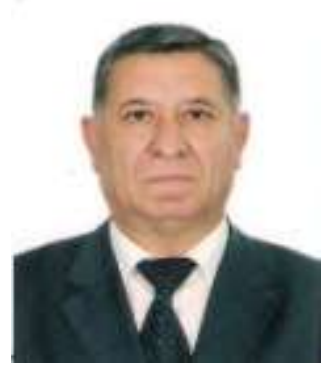

Dr. Aydin Mahammad Pashajanov is the head of laboratory "Analytical Chemistry" in the Institute of Catalysis and Inorganic Chemistry of Azerbaijan National Academy of Sciences. His scientific direction: study of complexation of metals with organic reagents, development of photometric, spectrophotometric and extraction-atomic-absorption methods of their determination. He is the author of more than 120 scientific works, including one monograph "Atomic-absorption spectroscopy". 